\title{
EFFECT OF HEAD-NECK POSTURE ON HUMAN DISCOMFORT DURING WBV
}

\author{
Jonathan DeShaw*, BSME; Salam Rahmatalla, PhD \\ Center for Computer-Aided Design (CCAD) \\ The University of Iowa, Iowa City, Iowa 52242
}

\section{Introduction}

It is well known that sitting posture is associated with discomfort and a number of musculoskeletal disorders such as low back pain (Adams et al., 1985). The problem becomes more acute in whole-body vibration (WBV) such as that encountered in farming and construction machinery (Griffin 1988). Seat manufacturers have made significant strides toward developing seats for equipment that help alleviate the vibration transferring to the lower area of the spine. While this is seen as a positive achievement, it is likely that the increased neck-head motion resulting from these seat designs was overlooked. Many cervical spine studies have been developed to estimate the response of the head and neck; however, these studies rarely take head and neck posture into account.

The objective of this work was to study and demonstrate the difference in human biomechanical response to WBV when using different neck postures. Four head-neck postures - up, down, to the side, and normal (straight forward) — were investigated.

\section{Methods}

Ten male subjects with ages ranging from 19 to 28 years were used to test each of the four postures using discrete sinusoidal frequencies of 2, 3, 4, 5, 6, 7, 8, and $9 \mathrm{~Hz}$ at constant amplitudes of $0.8 \mathrm{~m} / \mathrm{s}^{\wedge} 2 \mathrm{RMS}$ and $1.15 \mathrm{~m} / \mathrm{s}^{\wedge} 2 \mathrm{RMS}$. Written informed consent, as approved by the University of Iowa Institutional Review Board, was obtained prior to testing. Subjects were seated in a rigid seat rigidly mounted to a vibration platform as shown in Figure 1. Vibration was generated using a six-degree-of-freedom man-rated shaker table (the Moog-FCS 628-1800 sixdegree-of-freedom electrical motion system). In order to isolate the role of the back support and focus on the head-neck motion characteristics, the subjects were strapped to the seat

using a neoprene vest and 5 straps. Each discrete frequency was run in the x-direction (fore-and-aft) for $15 \mathrm{sec}$, with $5 \mathrm{sec}$ stationary breaks. Amplitude and posture combinations were randomized with each discrete frequency so that each subject experienced every combination. Subjects reported their headneck discomfort using the Borg CR-10 scale with each posture, and then gave a second discomfort rating for the normal posture for each combination. A twelve-camera Vicon motion capture system and crossbow accelerometers were used to acquire the motion of the seat, C7 vertebrae, and center of head.

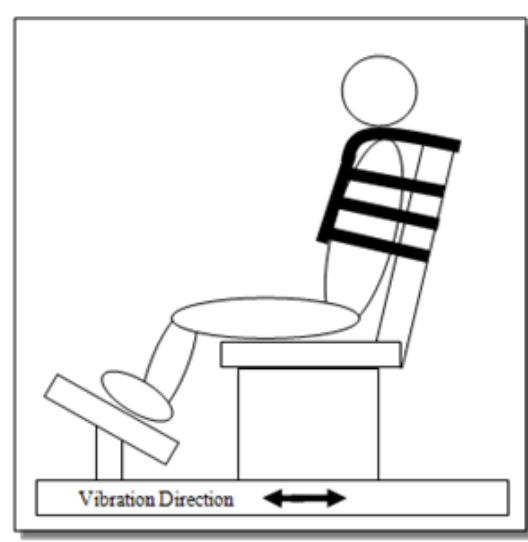

Figure 1 - Experiment Setup 


\section{Results}

Figure 2 shows the average subjective ratings of 10 subjects based on the Borg CR-10 scale in four different head-neck postures. In general, the normal head-neck posture showed a peak at 4 $\mathrm{Hz}$ and another peak around $6 \mathrm{~Hz}$. The up, down, and to-the-side postures showed similar trends with the first peak at $4 \mathrm{~Hz}$, but showed a shift in the second peak to a higher frequency (around 7 $\mathrm{Hz})$. After the first peak (4 $\mathrm{Hz}$ ), the up and to-the-side postures showed lower discomfort level compared to the normal posture; however, the head-down posture was very sensitive to frequencies higher than $4 \mathrm{~Hz}$ and showed a higher discomfort value in that region.

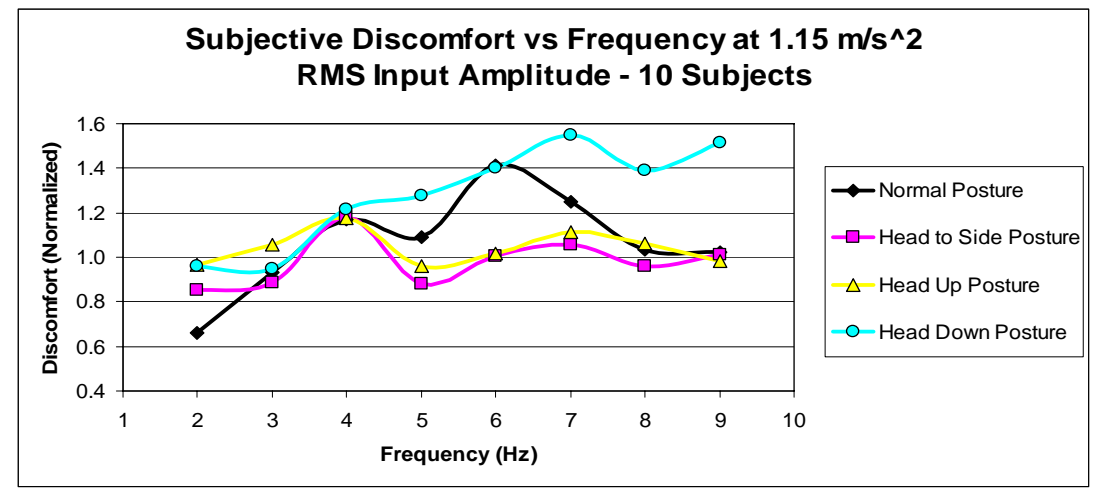

Figure 2: Average Discomfort of 10 Subjects at Discrete Frequencies 2-9 Hz

\section{Discussion}

The results have shown that the head-neck posture did not affect the location and the magnitude of the discomfort at the low frequency range, with the first peak at $4 \mathrm{~Hz}$ for all postures. However, the head-neck posture has a bigger role on head-neck motion and discomfort at higher frequencies. This is very clear in Figure 2, where the second peak in the discomfort was shifted to a higher peak around $7 \mathrm{~Hz}$. This might be related to stiffer systems or larger motions with more muscle involvement. For the head-down posture, the magnitude of the discomfort function was higher than for the normal posture. This could be associated with the difficulty of generating more muscle activity in that position to support the head-neck region, resulting in more uncontrolled uncomfortable motions. As shown in Figure 2, the discomfort value for the headdown posture increased steadily after $4 \mathrm{~Hz}$. The to-the-side and head-up postures showed less discomfort after the first peak at $4 \mathrm{~Hz}$, but their magnitudes approach the normal posture around $8 \mathrm{~Hz}$. In these postures, the subjects have more flexibility to use the major neck-back muscles to minimize the head-neck motion. This creates a stiffer system and may explain why there is a shift in the second peak in the to-the-side and head-up postures. This work has demonstrated the importance of considering the head-neck posture in future seat-design studies.

\section{References}

1. Paddan GS, Griffin MJ [1988]. Transmission of translational seat vibration to the head - II. Horizontal seat vibration. J. Biomechanics Vol. 21, pp. 199-206.

2. Adams MA, Hutton WC [1985]. The effect of posture on the lumbar spine. J. Bone Joint Surg. Vol. 67B, pp. 625-629. 